\section{Sobre revacunación anti-pertussis en Chile}

\section{About pertussis booster vaccination in Chile}

\section{Sr. Editor:}

En su dúplica ${ }^{1}$ (contrarréplica a nuestra primera carta de respuesta ${ }^{2}$ ), el Dr. Felipe Cabello nuevamente manifiesta su preocupación por el cambio del segundo refuerzo de vacuna antipertussis desde una formulación de células enteras, administrada a los 4 años, por una formulación acelular, administrada en primero básico, cambio propuesto por el Ministerio de Salud y apoyado por el Comité Consultivo de Inmunizaciones $(\mathrm{CCI})^{3}$. La dúplica señala que "se carece de evidencia cientifica para fundamentar meridianamente que el cambio de una vacuna por otra será beneficiosa para la población infantil expuesta a él", y que "pareciera que los únicos favorecidos con este cambio serán los laboratorios productores y comercializadores de las caras y medianamente efectivas vacunas acelulares" . Al respecto, el CCI ratifica su apoyo a la decisión ministerial, y profundiza los siguientes puntos:

- Estamos al tanto de la evidencia recientemente publicada que demuestra una mayor protección entre quienes han recibido como esquema primario en el primer año de vida vacuna de células enteras, comparado con quienes recibieron vacuna acelular ${ }^{4,5}$. Más aún, se ha postulado que la causa del brote ocurrido en Australia (2009-2011) , podría haber sido el cambio programático desde una vacuna de células enteras a una vacuna acelular. Sin embargo, es importante recordar que la modificación ministerial afectará únicamente al segundo refuerzo, manteniéndose en Chile la administración de cuatro dosis de vacuna de células enteras antes de los dos años de edad.

- El Dr. Cabello señala el tener "la sensación de que este

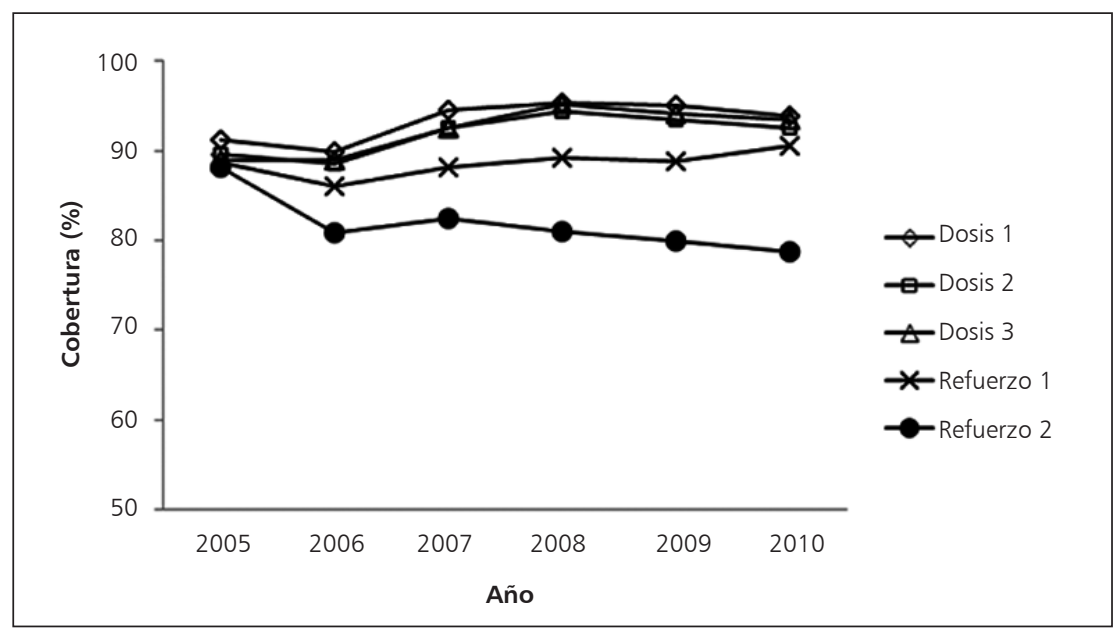

Figura 1. Cobertura de vacuna antipertussis, según dosis y año (Chile, 2005-2010)6. cambio se ha hecho para aumentar hipotéticamente la cobertura de vacunación antipertussis". Tenemos argumentos para afirmar que nuestro apoyo al cambio va más allá de una mera hipótesis. Datos nacionales reportados por el Departamento de Estadísticas e Información en Salud ${ }^{6}$ muestran que durante el período 2005-2010 la cobertura del segundo refuerzo de vacuna antipertussis ha experimentado una disminución desde $88,2 \%$ (2005) a 78,8\% (2010), siendo esta además la dosis de menor cobertura de las cinco administradas (Figura 1). A modo de comparación, durante el período 2005-2010 la cobertura de la segunda dosis de vacuna tresvírica (administrada en primero básico) fue persistentemente superior que la del segundo refuerzo de vacuna antipertussis (administrado a los 4 años). Esto podría ser atribuible a que la administración de vacunas en los colegios hace más fácil el acceso a la población beneficiaria. En términos absolutos, si el año 2010 el segundo refuerzo de vacuna antipertussis hubiese tenido la cobertura de la segunda dosis de vacuna tresvírica $(83,8 \%)$, la ganancia neta hubiese sido de 5 puntos porcentuales, equivalentes a un aumento de aprox. 12.000 niños vacunados a nivel nacional.

- Junto con aumentar la cobertura de vacunación, un hecho deseable es también aumentar la duración de la inmunidad. Por consiguiente, resulta razonable atrasar la administración del segundo refuerzo a primer año básico, considerando que en el esquema antiguo las vacunas administradas a los 18 meses y a los 4 años se encontraban bastante cercanas temporalmente (30 meses de diferencia). Dicho cambio necesariamente implica la administración de una vacuna acelular, pues a esa edad (6-7 años) el riesgo de reacciones adversas por la administración de una vacuna de células enteras resulta inaceptablemente alto ("lo primero es no dañar"). Es importante señalar que la modificación apoyada por el CCI está en sintonía con la introducción a partir de 2013 de vacunación universal antipertussis en octavo básico (13-14 años). Con estas medidas, el niño quedaría protegido gran parte de su infancia y adolescencia.

- Es importante señalar que el control de esta enfermedad es bastante complejo, así lo confirman las experiencias en otros países, los cuales han usado diversas estrategias (vacunación de adolescentes, estrategia "capullo"). Ello hace evidente la necesidad de desarrollar nuevas y mejores vacunas antipertussis; sin embargo, por el momento solamente es factible orientar los esfuerzos a extender la duración de la protección otorgada por las vacunas existentes y a mejorar las coberturas.

- Finalmente, en nuestra calidad de Comité Consultivo perteneciente a una sociedad científica, quisiéramos 
dejar claro que nuestro apoyo a la modificación ministerial obedece a una reflexión técnica sobre el tema, siendo nuestro fin último apoyar todas aquellas alternativas que ofrezcan el mayor grado de protección a la población. Al respecto, no es de nuestro interés ni preocupación el beneficio que ello pueda significar para los laboratorios productores y comercializadoras de vacunas.

Marcela Potin, Jaime Cerda, Alma Muñoz, Lily Contreras, Isabel Domínguez y Liliana Véliz Integrantes Comité Consultivo de Inmunizaciones Sociedad Chilena de Infectología.

\section{Referencias}

1.- Cabello F. Tos convulsiva epidémica y cambios en los esquemas de vacunación. Chile 2012. ¿Persisten las interrogantes? Rev Chilena Infectol 2013; 30 (2): 224.

2.- Potin M, Cerda J, Contreras L, Muñoz A, Ripoll E, Vergara R (en representación del comité Consultivo de Inmunizaciones, Sociedad Chilena de Infectología). Respuesta. Rev Chilena Infectol 2012; 29 (6): 694-5.

3.- Potin M, Cerda J, Contreras L, Muñoz A, Ripoll E, Vergara R. Modificación en el esquema de vacunación antipertussis en Chile, vacunación en grupos especiales y estrategias de control: Comentario del Comité Consultivo de Inmunizaciones (CCI) de la Sociedad Chilena de Infectología. Rev. Chilena Infectol 2012; 29(3): 307-11.

4.- Klein N, Bartlett J, Fireman B, Rowhani-Rahbar A, Baxter R. Comparative effectiveness of acellular versus whole-cell pertussis vaccines in teenagers. Pediatrics 2013; 131: e1716-22.

5.- Sheridan S L, Ware R S, Grimwood K, Lambert S B. Number and order of whole cell pertussis vaccines in infancy and disease protection. JAMA 2012; 308: 454-6.

6.- Departamento de Estadísticas e Información en Salud. Metodología y Cálculo Cobertura de Inmunizaciones (2005-2010). Disponible en www.deis.cl (accedido el 04/06/2013). 